Title: OVERVIEW OF THE BUMP-MAGNET SYSTEM AT THE LANSCE PROTON STORAGE RING

$\begin{array}{ll}\text { Author(s): } & \text { Chris R. Rose } \\ \text { David B. Barlow } & \text { LANSCE-1 } \\ \text { Barbara Blind } & \text { LANSCE-1 } \\ \text { Filippo Neri } & \text { LANSCE-1 } \\ \text { John F. Power } & \text { LANSCE-1 } \\ \text { Peter L. Walstrom } & \text { LANSCE-1 } \\ & \text { LANSCE-1 }\end{array}$

$$
\text { CONF. } 970503 \ldots-263
$$

Submitted To: 1997 Particle Accelerator Conference Vancouver BC, Canada

May 12-16, 1997

\section{RECEIVED}

IIII +41007

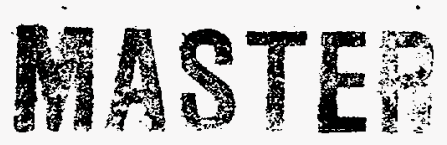

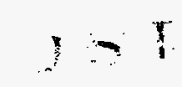

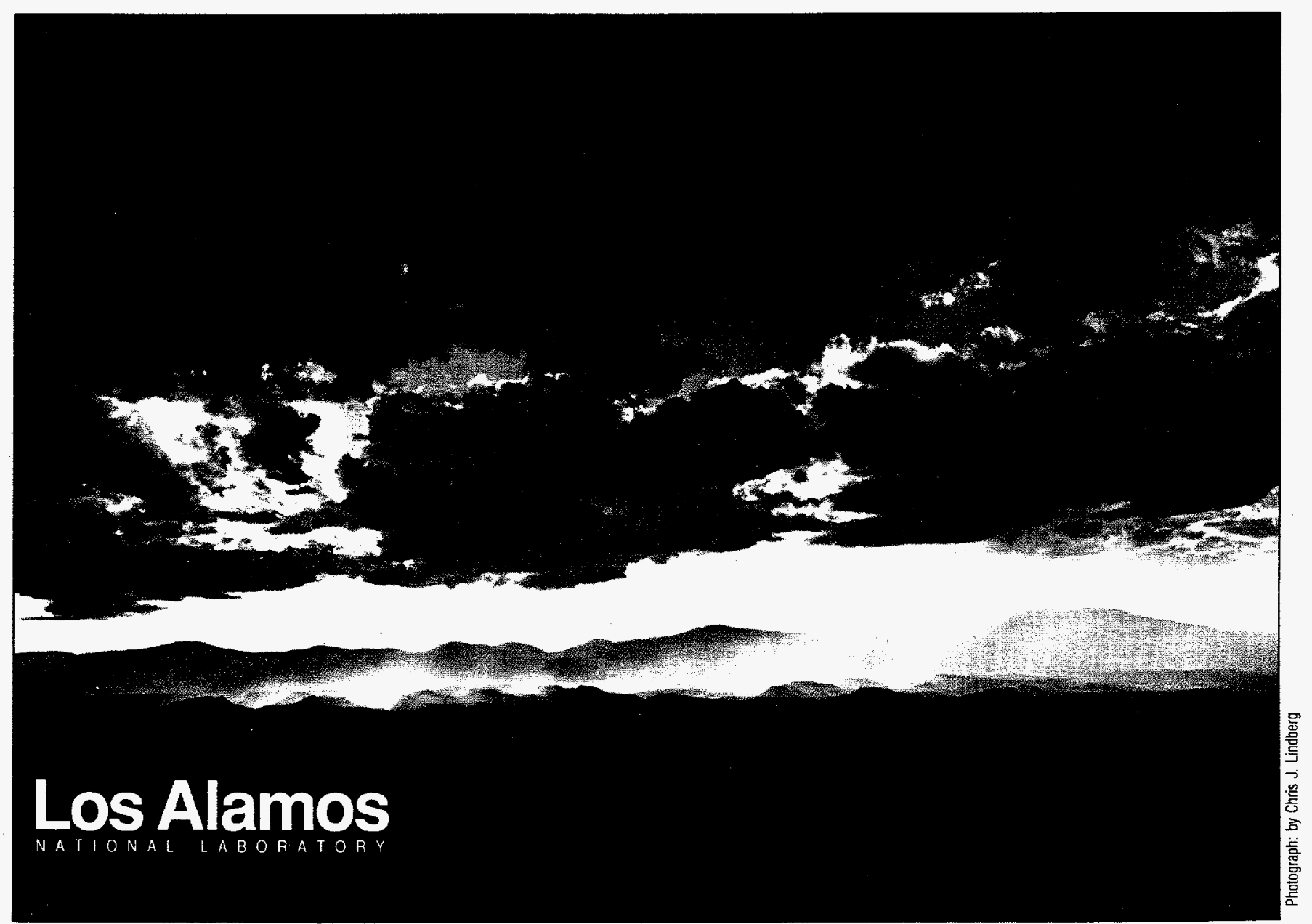

This is a preprint of a paper intended for publication in a journal or proceedings. Because changes may be made belore publication, this preprint is made available with the understanding that it will not be cited or reproduced without the permission of the author. 


\title{
OVERVIEW OF THE BUMP-MAGNET SYSTEM AT THE LANSCE PROTON STORAGE RING
}

\author{
C. R. Rose, D. B. Barlow, B. Blind, F. Neri, J. F. Power, and P. L. Walstrom \\ Los Alamos National Laboratory, Los Alamos, NM 87545
}

Abstract

An upgrade program for increasing the stored beam current in the Proton Storage is presently under way. A part of the upgrade is the design and installation of a four-magnet beam-bumping system used for phase-space painting and minimizing interaction of the stored beam with the injection stripper foil. This paper describes the bump-magnet system including the relevant beam requirements, magnet specifications, power-cable specifications, pulsed-modulator requirements, and beam-tube eddy-current effects. The magnets are ferrite window-frame magnets with saddle windings. The series-pass pulsed modulators are programmable both in rise and fall time as well as amplitude. The peak current can be varied between 50 and $300 \mathrm{~A}$. The pulsed-current rise-time is fixed at $1 \mathrm{~ms}$, and the linear fall-time during which beam is injected into the ring can be varied between 0.5 and $1.5 \mathrm{~ms}$.

\section{SYSTEM OVERVIEW}

The purpose of the bump-magnet modulator system is to "paint" the injected beam into the storage ring. To do this, four bump magnets are used that have precisely controlled; linear-decaying magnetic fields that move the injected beam into the ring synchronously with the ringorbit cycle. The beam is bumped in the vertical plane. The maximum field strength in any one magnet is on the order of 500 gauss, and each of the four magnets is pulsed at different field levels with respect to the others. The magnetic field strength of 500 gauss translates roughly to 300 A peak current in the magnets. A simplified view of one modulator/cable/magnet system is shown below in Fig. 1.

The required current waveshape is depicted next to the waveform generator. It has a linear risetime, a flattop, and a linear decay time. The decay time is variable from 0.5 to $1.5 \mathrm{~ms}$. The amplitude can be varied from 50 to $300 \mathrm{~A}$.

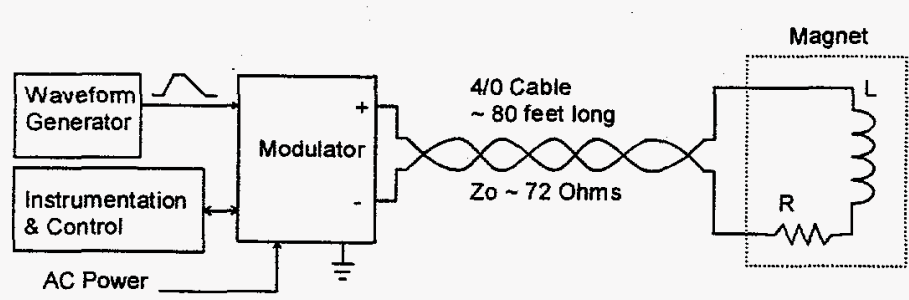

Fig. 1 Block diagram of one bump-magnet system.

\section{BUMP MAGNETS}

The four bump magnets are fast-slewing smalldeflection dipole magnets. In order to minimize design and prototype development costs; a single magnet design is used for all four magnets. This standardized design produces a field strength of 488 gauss (at $300 \mathrm{~A}$ ) which is sufficient to produce a deflection of $3 \mathrm{mrad}$ for 800 $\mathrm{MeV}$ protons. Important magnet parameters are: $30-\mathrm{cm}$ length, $12 \mathrm{~cm}$ by $12 \mathrm{~cm}$ clear aperture, 16 turns, and $140-$ $\mu \mathrm{H}$ inductance. A drawing of the magnet is shown in Fig. 2.

Ferrite-yoke magnets were chosen on the basis of

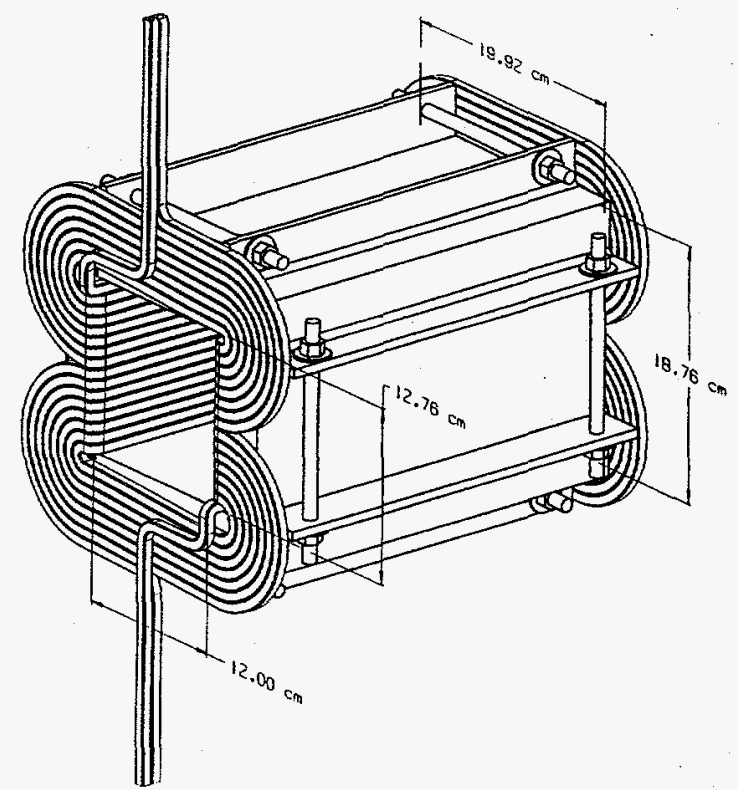

Fig. 2 Diagram of the bump magnet with dimensions.

their lighter weight, smaller size, and lower overall cost compared to tape-wound-core magnets. A Ceramic Magnetics Inc. MN60 magnetically-soft manganese-zinc ferrite with an initial relative permeability of 6500 , a maximum flux density of $0.45 \mathrm{~T}$, and a coercive force of 0.08 oersteds was chosen for the magnet. At this frequency and flux density, the continuous power loss is less than $1 \mathrm{~mW} / \mathrm{cm}^{3}$. When the duty-cycle (about 3\% for a typical magnet power cycle) is factored in, the average ferrite power loss is negligible. The magnet yoke is made from four ferrite pieces with steps in two of the pieces to lock the pieces together when pressed by an external 
clamping structure. The magnet windings are singlelayer epoxy-potted saddle coils of insulated square copper conductor with a circular internal cooling channel. Resistive power losses in the windings are small enough to be easily removed by air or water cooling.

The largest magnet-related power losses are expected to be in the beam pipe running through the bore of the magnet. Eddy currents in the tube not only cause a power loss but also affect the field within the tube. It is important that the field perturbations be minimized. In the pipe, a characteristic decay time of dipole eddy currents of 15 microseconds or less is allowable. In order to provide a thinenough wall to minimize the eddy currents and to simultaneously withstand external pressure when the pipe is evacuated, we have chosen to use a $0.2 \mathrm{~mm}(0.008 \mathrm{in}$.)wall 316 stainless-steel formed bellows for the beam pipe within the magnet. The dutycycle averaged eddy-current power for this pipe is estimated to be about 50 watts at 60 $\mathrm{Hz}$ repetition frequency. This amount of power can be removed by natural air convection.

The first of the five magnets (four for installation and one backup) has been fabricated by Everson Electric Company and delivered to Los Alamos.

\section{MODULATORS}

To date, Los Alamos National Laboratory has received one of the five modulators from the vendor, Dynapower Corporation, to be used in the complete bump system. It has been connected to the magnet as shown in Fig. 1 and data taken. In the final system, the peak current of each magnet is independently adjusted while maintaining the same functional shape. In addition, when or if needed (or desired) the waveform of each magnet's current can be slightly adjusted or shaped because each modulator will be controlled by a separate programmable-waveform generator. However, in all cases, the timing of all four modulators will be synchronized. An actual current waveform from the first modulator and magnet pair is shown in Fig. 3. The top waveform is the magnet current, and the bottom waveform is the voltage across the magnet. The leadingedge risetime will be fixed at about $1 \mathrm{~ms}$. The ring injection takes place during the down-trending portion of the waveform. It is this portion that must be accurately and repeatedly controlled to ensure accurate and repeatable beam bumping. Each of the four magnets requires different magnetic-field strengths, and different electric-current values. During the leading edge and flat- top, the magnet is energized and brought to the desired current and field level. The flat-top is a holding period used to synchronize the bump system to the ring injection system from which it receives a timing pulse and begins the down ramp.

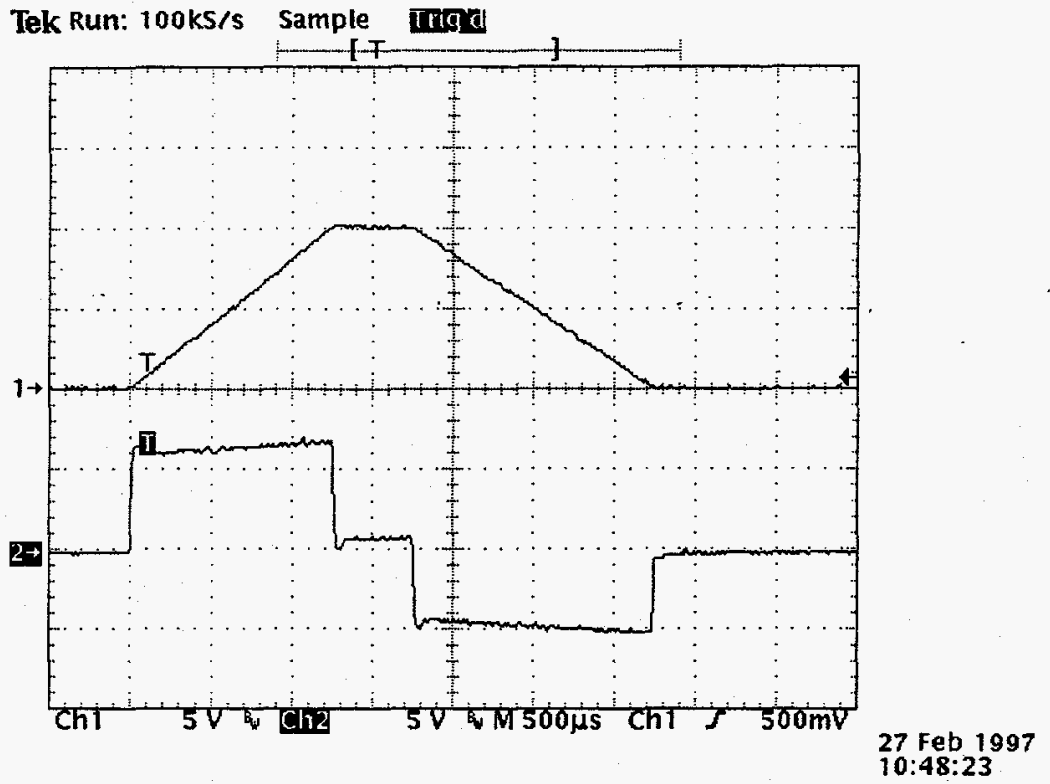

27 Feb 1997
$10: 48: 23$

across the magnet. Top scale: $30 \mathrm{~A} / \mathrm{V}$. Bottom: $10 \mathrm{~V} / \mathrm{V}$.

\section{CONCLUSIONS}

At present, there is one operating bump system at Los Alamos from which data has been taken. The first magnet and modulator have been connected together and operated at full current and full repetition rate of $60 \mathrm{~Hz}$. Test data show that the error between the programmed current and actual current is less than one percent at the corners which is twice as good as the specified accuracy, and less than 0.2 percent during the smooth parts of the function. The first bump magnet has been field mapped, and the integral field varied less than one percent across the bore of the aperture. The remaining magnets and modulators are presently on order from the respective vendors and are scheduled for installation during the Fall of 1997. 


\section{DISCLAIMER}

This report was prepared as an account of work sponsored by an agency of the United States Government. Neither the United States Government nor any agency thereof, nor any of their employees, make any warranty, express or implied, or assumes any legal liability or responsibility for the accuracy, completeness, or usefulness of any information, apparatus, product, or process disclosed, or represents that its use would not infringe privately owned rights. Reference herein to any specific commercial product, process, or service by trade name, trademark, manufacturer, or otherwise does not necessarily constitute or imply its endorsement, recommendation, or favoring by the United States Government or any agency thereof. The views and opinions of authors expressed herein do not necessar. ily state or reflect those of the United States Government or any agency thereof. 


\section{DISCLAMMER}

Portions of this document may be illegible in electronic image products. Images are produced from the best available original docoument. 